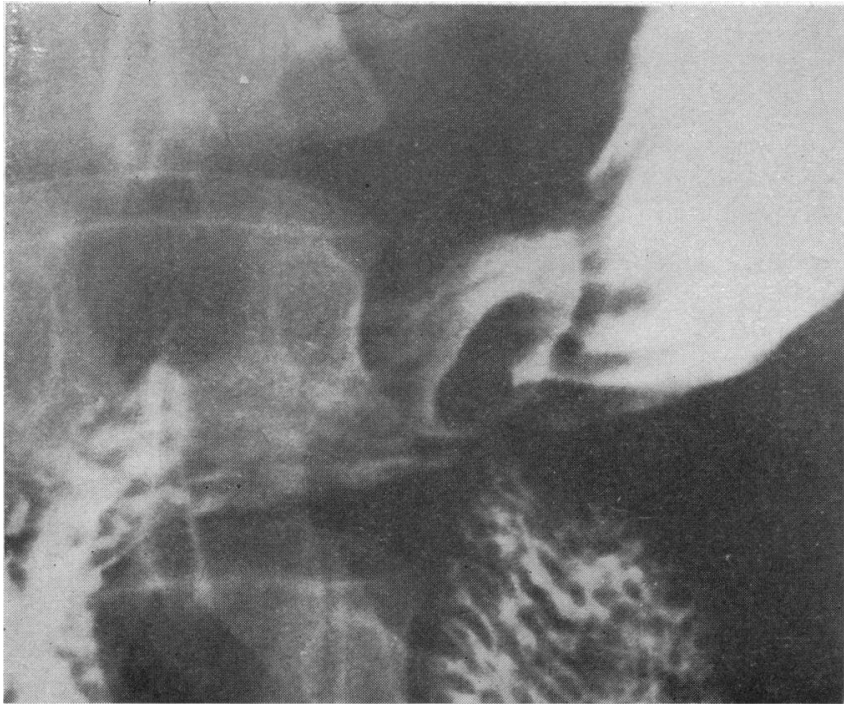

Fig. 1.-Case 1. Gastro-duodenal mucosal prolapse.

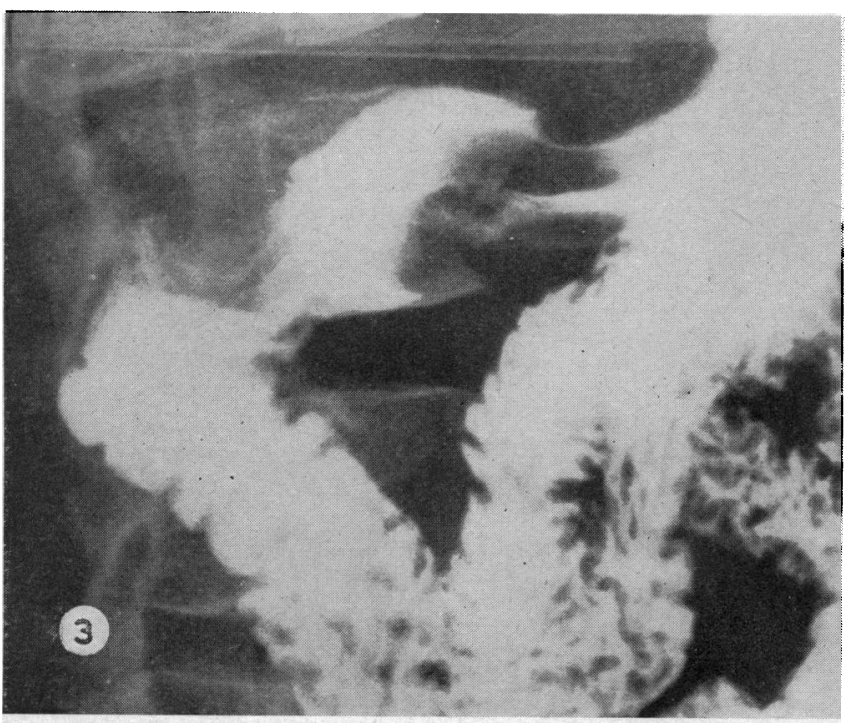

Fig. 3.-Case 3. Gastro-duodenal mucosal prolapse.

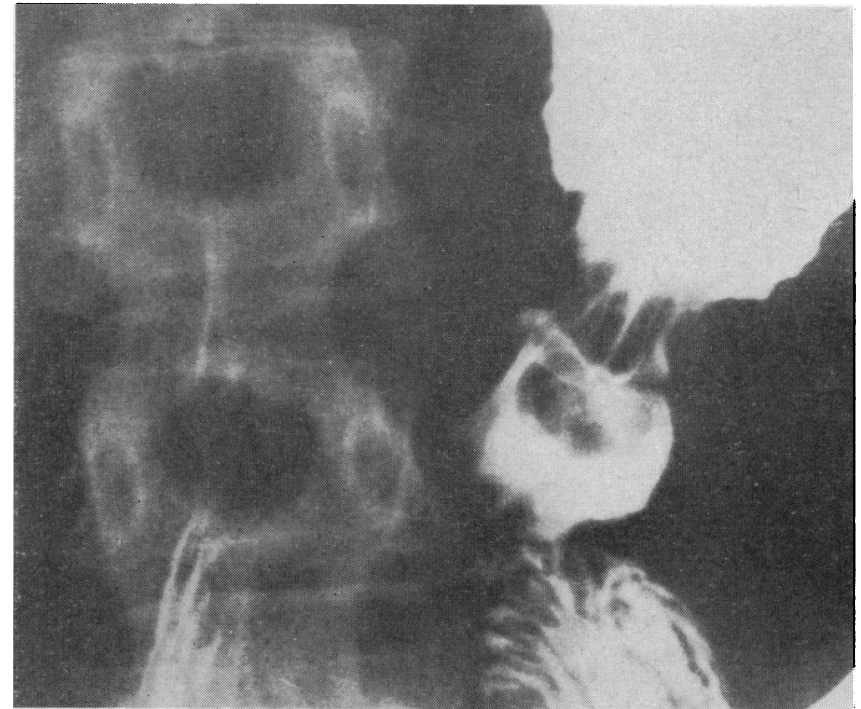

FIG. 2.-Case 2. Gastro-duodenal mucosal prolapse.

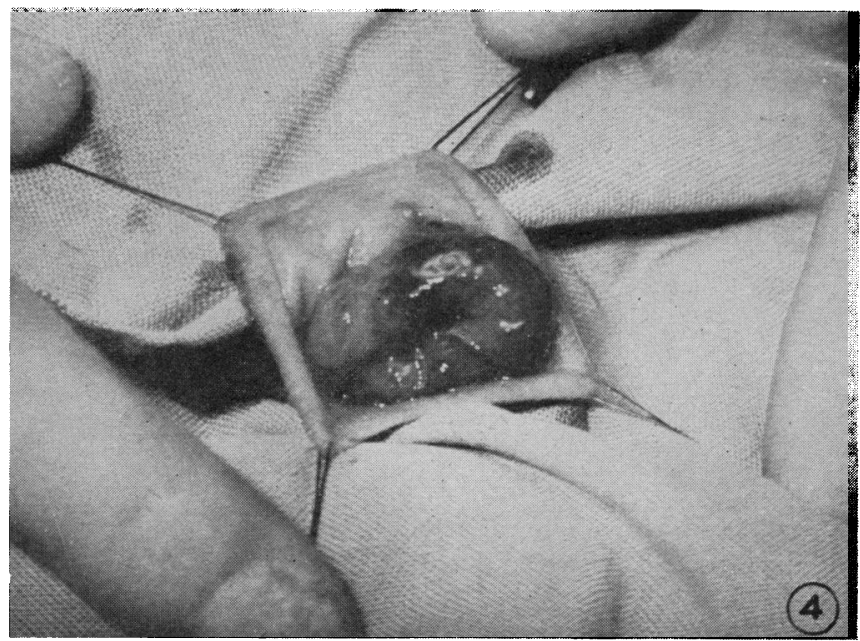

Fig. 4.-Case 3. Appearance of mucosal prolapse at operation viewed from the duodenal aspect.

Fig. 1.-Case 1. Pseudo-fractures in right fourth and fifth ribs and left scapula.

D. J. C. FELTON AND W. D. STONE : OSTEOMALACIA IN ASIAN IMMIGRANTS DURING PREGNANCY

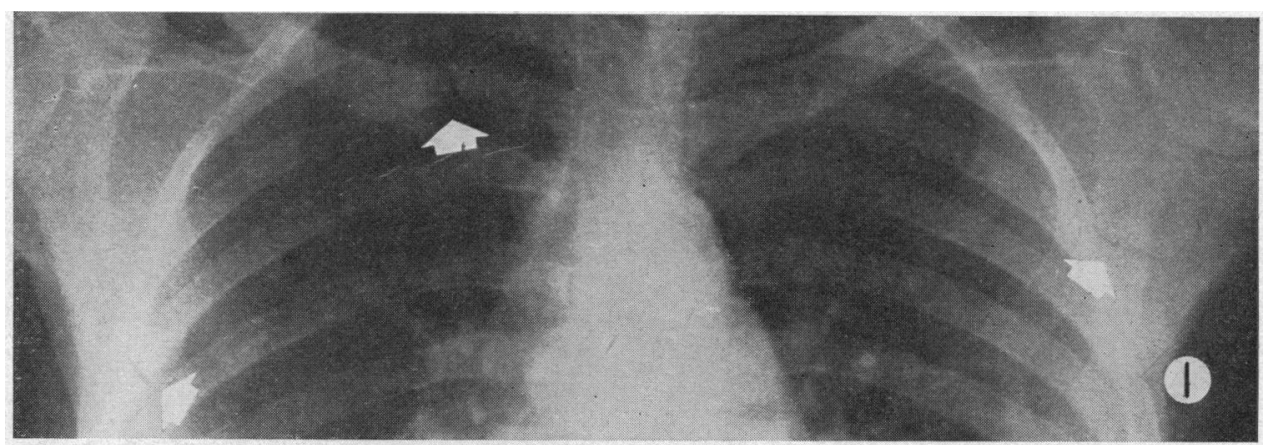

FIG. 2.-Case 3. Pseudo-fractures of both eleventh ribs. 
reovirus type 3. One of the others appears to be herpes simplex, while the twelfth has not yet been identified. The appearance of these reovirus strains in the electron microscope and their effects on mice were characteristic, and it is concluded that reovirus is associated with at least a proportion of the cases of Burkitt's lymphoma. The implications of these findings are discussed in the light of new epidemiological evidence.

We wish to thank Dr. G. F. Marrian, Director, Imperial Cancer Research Fund; Dr. R. J. C. Harris, Head of Division of Experimental Biology and Virology; the Director, E.A. Virus Research Institute ; and Professor D. B. Allbrook, Anatomy Department, Makerere University College, for their help and encouragement throughout the survey. We are grateful to Mr. D. P. Burkitt and Mr. S. Kyalwazi, Department of Surgery, Makerere University College ; Mr. C. Patel, Regional Medical Officer, Mwanza, and Dr. J. Maitland, Freda Carr Hospital, Ngora, for the supply of tumour tissue; and to Professor M. S. R. Hutt and Dr. D. H. Wright, Pathology Department, Makerere University College, for histological confirmation. We appreciate the supply of serum specimens from Mr. P. P. Clifford, Kenyatta National Hospital, Nairobi ; of human embryonic tissue from Dr. H. E. M. Kay, Royal Marsden Hospital, London; and of monkeys from Mr. T. Mann, Entebbe.

This work was supported in part by a grant from the Leverhulme Trust. The electron-microscopical work was done in the Wellcome Electron Microscope Laboratory, and the expenses were defrayed by a grant from the Tropical Medical Research Board of the Medical Research Council.

\section{REFERENCES}

Allbrook, D. B., Wright, D. H., and Griffin, E. R. (1966). To be published.

Andrewes, C. H. (1962). Advances in Virus Research, vol. 9, edited by K. M. Smith and M. A. Lauffer. Academic Press, New York and London.

Bell, T. M. (1962). Scot. med. 7., 7, 85.
(1965). An Introduction to General Virology, chapt. 12, p. 95. Heinemann, London.

- Massie, A., Ross, M. G. R., and Williams, M. C. (1964). Brit. med. 7., 1, 1212 .

and Ross, M. G. R. (1966). In press.

— and Steyn, J. H. (1962). Brit. med. F., 2, 700.

Benyesh-Melnick, M., Rosenberg, H. S., and Watson, B. (1964). Proc. Soc. exp. Biol. (N.Y.), 117, 452 .

Burkitt, D. P. (1962). Postgrad. med. 7., 38, 71.

- and Wright, D. H. (1966). To be published.

Dalldorf, G., and Bergamini, F. (1964). Proc. nat. Acad. Sci. (Wash.), $51,263$.

Dorfman, R. F. (1965). Cancer, 18, 418.

Epstein, M. A., Achong, B. G., and Barr, Y. M. (1964). Lancet, 1, 702. - and Barr, Y. M. (1965). 7. nat. Cancer Inst., 34, 231.

Girardi, A. J., Slotnick, V. B., and Hilleman, M. R. (1962). Proc. Soc. exp. Biol. (N.Y.), 110, 776.

Haddow, A. J. (1963). E. Afr. med. F., 40, 429.

- (1964). Ibid., 41, 1.

Harris, R. J. C. (1964). Brit. med. Bull., 20, 149.

Lunger, P. D. (1964). Virology, 24, 138.

McAllister, R. M., Mikenas, M., Straw, R. M., and Landing, B. H. (1963). Lab. Invest., 12, 342.

Moore, A. E. (1962). Virology, 18, 182.

O’Conor, G. T., Rappaport, H., and Smith, E. B. (1965). Cancer, 18, 411.

Parker, L., Baker, E., and Stanley, N. F. (1965). Aust. F. exp. Biol. med. Sci., 43, 167.

Payne, F. E., Beals, T. F., and Preston, R. E. (1964). Virology, 23, 109.

Rowe, W. P., Hartley, J. W., Waterman, S. Turner, H. C., and Huebner, R. J. (1956). Proc. Soc. exp. Biol. (N.Y.), 92, 418.

Huebner, R. J., Gilmore, L. K., Parrott, R. H., and Ward, T. G. (1953). Ibid., 84, 570 .

Simons, P. J., and Ross, M. G. R. (1965). Europ. F. Cancer, 1, 135.

Smith, M. G. (1956). Proc. Soc. exp. Biol. (N.Y.), 92, 424.

Stewart, S. E., Lovelace, E., Whang, J. J., and Ngu, V. A. (1965). 7. nat. Cancer Inst., 34, 319.

ten Seldam, R. E. J., Cooke, R. A., and Atkinson, L. (1966). Cancer, $19,437$.

Vasquez, C., and Tournier, P. (1962). Virology, 17, 503.

Woodall, J. P., Williams, M. C., Simpson, D. I. H., and Haddow, A. J. (1965). Europ. 7. Cancer, 1, 137.

Wright, D. H. (1965). Israel f. med. Sci., 1, 177.

\title{
Gastro-duodenal Mucosal Prolapse After Billroth I Gastrectomy
}

\author{
G. P. G. SIM,* M.B., CH.B., F.F.R., D.M.R.D., M.C.R.A.
}

[With Special Plate]

Brit. med. F., 1966, 1, 1517-1518

Prolapse of mucosa through the orifices of the stomach is of recurrent interest, but the particular complication of mucosal prolapse after Billroth I partial gastrectomy has received little notice. This paper refers to three cases of gastro-duodenal mucosal prolapse diagnosed in a period of eight months by barium-meal examination. Each patient had previously undergone gastrectomy of the Billroth I type, and one subsequently underwent further surgery at which prolapse was confirmed and resected.

\section{Case 1}

A man aged 45 had a history of dyspepsia dating back to 1952 . An ulcer had been seen on the lesser curve of the stomach at gastroscopy in October 1961, and a Billroth I partial gastrectomy was performed in August 1962. In July 1964 he complained of nausea of two months' duration, especially in the morning, together with a constant ache in the mid-abdomen and left loin. There was no history of intestinal bleeding. His haemoglobin was 14.0 g./

* $X$-ray Department, Wellington Hospital, Wellington, New Zealand.
$100 \mathrm{ml}$. Barium-meal examination showed changes in the gastroduodenal junction consistent with prolapse of gastric mucosa (Special Plate, Fig. 1) but no other abnormality.

His subsequent history includes further intermittent bouts of abdominal pain.

\section{Case 2}

A woman of 58 had a haematemesis in September 1949, when a barium-meal examination showed a duodenal ulcer. A further haematemesis occurred in September 1960. In November of the same year a Billroth I type partial gastrectomy was carried out with removal of more than two-thirds of the stomach. In August 1964 she was admitted to hospital because of two melaena stools in three days and abdominal pain for two weeks. This pain, sometimes severe, was epigastric in situation and occurred before and after meals. Faeces were strongly positive for occult blood. The haemoglobin level was $10.5 \mathrm{~g} . / 100 \mathrm{ml}$. A barium-meal report stated: "A smooth, roughly hemispherical filling defect protrudes into the commencement of the duodenum from the region of the anastomosis. This appearance is consistent with prolapse of the gastric mucosa" (Special Plate, Fig. 2). 
The pain settled on medical treatment, the faeces became negative for occult blood, and a month later the haemoglobin was 11.5 g. $/ 100 \mathrm{ml}$.

\section{Case 3}

A woman aged 37 originally underwent gastric surgery in June 1962 for a chronic duodenal ulcer. The operation was a vagotomy and antrectomy with a Billroth I type of reconstruction. She was referred for surgical review in April 1965, complaining of having had abdominal pains since early 1963. These had become almost continuous during the previous three months. On three occasions severe bouts of epigastric pain lasting two to three hours had been followed by the passage of jet-black stools. At the time of review her haemoglobin level was $10.6 \mathrm{~g} . / 100 \mathrm{ml}$. with normochromic red cells. Barium-meal examination showed an abnormality consistent with prolapse of the gastric mucosa across the gastro-duodenal junction (Special Plate, Fig 3). A test meal produced only a trace of acid after $100 \mathrm{mg}$. of Histalog (ametazole hydrochloride). At gastroscopy the stoma was healthy and the mucosal folds were rather generally injected.

Surgery on 17 May 1965 confirmed the presence of prolapsing mucosa into the duodenum. This could be felt through the intact stomach and duodenal walls and was from the greater curve. The lesser-curve mucosa did not prolapse. On opening the duodenum below the anastomosis the prolapsing mucosa could be seen projecting through the stoma (Special Plate, Fig. 4). It was deeply congested and bleeding a little. The gastrectomy was converted to one of the Polya type, and the segment containing the original anastomosis excised. The pathological report stated: "The specimen consists of excised prolapsing gastric mucosa. The cylindrical length of the specimen is $4 \mathrm{~cm}$. in its maximum part. The gastric mucosa at the site of prolapse is grossly hypertrophied. The microscopical diagnosis is giant hypertrophic gastritis."

In the three months following operation there have been occasional episodes of abdominal pain but no evidence of further bleeding.

\section{Discussion}

Abnormal movement of mucosa in both directions at the cardia has been observed by Feldman (1951) and by Sarasin and Hoch (1951), who described gastro-oesophageal and oesophago-gastric mucosal prolapse respectively. Schmieden recorded prolapse of gastric mucosa through the pylorus in the intact stomach as early as 1911 , while more recently Mendl and Sharp (1960) have noted retrograde prolapse through the pylorus of redundant duodenal mucosal folds. The descriptions of gastro-jejunal mucosal prolapse following partial gastrectomy include those of Le Vine, Boley, Mellins, and Schwartz (1963) and of Grimoud, Moreau, and Lemozy (1964). Jejuno-gastric intussusception has been the subject of many papers since that of Shackman (1940).

$\mathrm{H}$. and A. Monges (1958) presented a case of evagination of the gastric mucosa into the duodenum apparent on radiological examination two years after a Péan-type gastrectomy. Four years later the findings were similar. This prolapse corresponds to that described in the present paper.

The $x$-ray appearances in the three cases recorded above are those of a slightly lobulated intraluminal mass projecting across the gastro-duodenal anastomosis. Films made during different stages of peristalsis may show that the mass varies in size and it may disappear. Such films are of assistance in excluding malignancy. The prominent parallel mucosal folds traversing the stoma are unlike the changes of anastomotic ulcer.

Though the cause of this entity is a matter of speculation, it is useful to refer to the views of Grimoud et al. (1964) on the pathology of gastro-jejunal prolapse. They believe the two fundamental lesions to be abnormal mobility of the gastric mucosa on the submucosa, with movement even up to $5 \mathrm{~cm}$., and hypertrophy of the gastric mucosal folds, the latter being the initiating factor in the prolapse and not the result of it. In this context the gross and microscopical pathological finding of hypertrophic gastric mucosa in Case 3 is of interest. Referring again to the gastro-jejunal stoma, the same authors state that partial circumferential prolapse is more frequent than total prolapse. In Case 3 of the present series the prolapsed gastric mucosa was from the greater curve.

Evaluation of the clinical significance will require a larger number of cases. In the three cases described above abdominal pain was present but without a characteristic pattern. Surgical treatment in one case did not abolish the pain. However, post-operative gastro-duodenal mucosal prolapse as a cause of intestinal bleeding seems likely. Melaena and reduced haemoglobin levels were present in Cases 2 and 3, with mucosal prolapse the only other relevant abnormality demonstrated. In one of these patients actual bleeding from the prolapsed mucosa was seen at operation. In their nine cases of gastrojejunal prolapse Le Vine et al. (1963) include two patients who had intestinal bleeding, one with operative findings very similar to those of Case 3 .

\section{Conclusions and Summary}

Although gastro-duodenal mucosal prolapse after Billroth I type gastrectomy has received scant attention in the literature, the demonstration of three cases in a period of eight months by one examiner suggests that it may not be a rare condition.

Surgical and pathological findings are available in one of the present cases.

Any relationship of this condition to abdominal pain is not obvious in the present small series, but such prolapse may be a relevant finding in intestinal bleeding.

I am grateful to Dr. A. C. D. Parsons for the clinical findings in Case 1, to Dr. A. E. Erenstrom for those in Case 2, to $\mathrm{Mr}$. A. F. Gordon Anderson for clinical and surgical details of Case 3, and to Dr. B. A. Scobie for his criticism of the manuscript.

\section{REFERENCES}

Feldman, M. (1951). Amer. f. med. Sci., 222, 54. Grimoud, M., Moreau, G., and Lemozy, J. (1964). Arch. Mal. Appar. dig., 53, 649. Le Vine, M., Boley, S. J., Mellins, H. Z., and Schwartz, S. S. (1963).
Radiology, 80, 30.

Mendl, K., and Sharp, M. E. (1960). Brit. F. Radiol., 33, 36.

Monges, H. and A. (1958). Arch. Mal. Appar. dig., 47, 201.

Sarasin, R., and Hoch, A. (1951). Schweiz. med. Wschr., 81, 1207.

Schmieden, V. (1911). Arch. klin. Chir., 96, 253.

Shackman, R. (1940). Brit. F. Surg., 27, 475. 